umbilicus, hard and resisting, and with no signs of fluctuation discoverable, but on the 17 th a doubtful spot

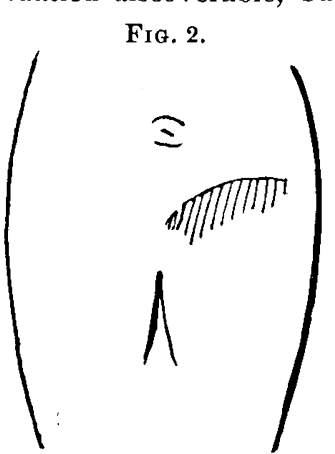

Situation and Extent of

Effusion as shown by Abdominal Palpation October 10,1881 .

ed. After discharging freely the opening closed, and, the sac not refilling, December 4 th was able to sit up.

December 31st. Uterus was found to be movable, with very slight posterior adhesions, no remains of induration or swelling to be found, and the large sacral sore nearly closed. She was allowed to remain in the hospital for a time to regain her strength. When able to leave her bed she found herself with partial loss of both notion and sensation in the lower extremities, which it required nearly two months to recover from, probably from granular muscular degeneration after such protracted high temperature.

Noтє. The suddenness of the attack when apparently well and two weeks after a normal confinement would suggest a hæmorrhagic origin, but whether hæmorrhagic or septic the early pointing and evacuation doubtless saved her from extensive consolidation of the pelvic tissues, aind probably from much future trouble, as there remains no discoverable induration by external or internal examination in the lateral regions of the pelvis. The uterus is freely movable, the posterior adhesions being too trifling to cause any inierference.

\section{REPORT OF THE COMMITTEE ON METEOROL-} OGY AND EPIDEMICS FOR THE YEAR 1880, IN PHILADEL,PHIA. ${ }^{1}$

\author{
BY RICHARD A. CLEEMANN, M. D. \\ Member of the Board of Health of Philadelphia.
}

Temperature. - The mean annual temperature of the year 1880, as calculated from the monthly means, was $54.6^{\circ} \mathrm{F}$. (Table $\mathrm{A}$ ), or $1.7^{\circ} \mathrm{F}$. above the average for the nine years $1872-1880$ : the year was, then, taken as a whole, a warm one; indeed, during these nine years there was but one for which a higher mean tenuperature was recorded, 1878 , when $54.7^{\circ} \mathrm{F}$. was attained (Table B).

The first six months of the year, and September, each exceeded their respective averages of mean temperature during nine years. January, with the mean reading of the thermometer for the month at $41^{\circ} \mathrm{F}$., went beyond its average as much as $8.7^{\circ} \mathrm{F}$., and the mean of $39.1^{\circ} \mathrm{F}$. for February was $6.1^{\circ} \mathrm{F}$. above its average; so that the winter was wonderfully mild for

1 From advance sheets. Read December 7, 1881. this climate. A greater warmth of the spring was not so marked, except at the close, the monthly means of temperature in the several months being for March $39.6^{\circ} \mathrm{F}$., for April 52.4 $\mathrm{F}$, and for May $68.8^{\circ} \mathrm{F}$., or respectively $.7^{\circ} \mathrm{F} ., 3.3^{\circ} \mathrm{F}$, and $6.9^{\circ} \mathrm{F}$. above their averages. So high a degree of heat in May was very exceptional, the mean temperature of the month in no one of the previous eight years rising within $7^{\circ} \mathrm{F}$. of this value. On the other hand, the months in the latter half of the year, with the exception of September, already mentioned, were each of lower temperature than usual, December being very cold. The fact that June, marking a mean of $73.8^{\circ} \mathrm{F}$. exceeded its average $2.3^{\circ} \mathrm{F}$., while July, recording $75.6^{\circ} \mathrm{F}$., and August $72.8^{\circ} \mathrm{F}$. were respectively $1^{\circ} \mathrm{F}$. and $6^{\circ} \mathrm{F}$. below their means, led to the summer being more equable than we are accustomed to find it. The fall, on the contrary, showed a greater variation in temperature between the months than is common, the $67.9^{\circ}$ F. of mean temperature of September being $1.6^{\circ} \mathrm{F}$. above its average, while the $55.1 \circ \mathrm{F}$. of October and the $40.5^{\circ} \mathrm{F}$. of November were respectively $.9^{\circ} \mathrm{F}$. and $2^{\circ} \mathrm{F}$. below their means. The mean temperature of December, $28.6^{\circ} \mathrm{F}$., is as much as $5.4^{\circ} \mathrm{F}$. below its average for vine years, and is, with the exception of that for 1876, the lowest recorded for the month during that period.

The range of the thermometer during the year was through $101^{\circ} \mathrm{F}$. of temperature; from $96^{\circ} \mathrm{F}$. recorded in May to $-5^{\circ} \mathrm{F}$. noted in December. The month of May was distinguished by the widest variation in temperature, the thermometric range being through $60^{\circ} \mathrm{F}$, and August by the narrowest, $34^{\circ} \mathrm{F}$.; between these two the other months came in the following order: July with a range of $30^{\circ} \mathrm{F}$.. September of $41^{\circ}$ $\mathrm{F}$, June of $43^{\circ} \mathrm{F}$., January of $44^{\circ} \mathrm{F}$., October of $47^{\circ}$ F., April of $52 \circ$ F., February of $55^{\circ}$ F., March, also. of $55^{\circ} \mathrm{F}$., December of $57^{\circ} \mathrm{F}$., and November of $59^{\circ}$ F. This is nearly the usual sequence of the months as far as those of the summer and September are concerned, this season being the most equable of the year in Philadelphia ; the absence of extremely cold weather in Jauuary, however, has given it an uncommonly high place in the list, while the warm spring has done a like thing for April ; on the other hand, the premature approach of summer in May carried the range of this month much beyond its usual extent, and the early winter had a similar effect upon November. No frost was observed in the fall until the $3 \mathrm{~d}$ of November.

Pressure. - The mean reading of the barometer for 1880 was 30.092 inches, which is .039 of an inch above the average for nine years, and the highest annual mean recorded during that period. In each of the months, with the exception of September and December, the mean monthly pressure was higher than the average, varying from an excess of .004 of an inch in July, to as much as .153 of an inch in November. The highest means are found, as a rule, in the winter months, and the lowest in the summer; but there was an exception this year as regards December, for notwithstanding the unusually low temperature of the month its mean barometric pressure was but 30.048 inches, exceeding only the respective means of April, June, and July.

The range of the barometer was through 1.612 inches, from 29.163 inches, the lowest point reached in February, to 30.775 inches, the highest recorded in 
November. The former month was distinguished by the greatest barometric range, 1.474 inches, and July by the least, .854 of an inch. In general, the cold months were less equable as regards pressure than the warm ones.

Rainfall. - Only 33.58 inches of rain were recorded in 1880 , or 8.36 inches less than the average precipitation during nine years; this is the least annual rainfall recorded in the Table which covers that period. The whole number of days on which rain or snow fell was 122 , the average for eight years being 133 . The lack in precipitation was divided, in unequal portions, among all the months save three, March, July, and December; the latter exceeded their averages, March very slightly, December 1.37 inches, and July as much as 2.52 inches, its rainfall of 7.74 inches being the highest recorded for any of the months. The least precipitation belonged to the exceptionally hot May, only .54 of an inch; from this value the months advanced as follows: September 1.10 inches, January 1.51 inches, June 1.67 inches, October 1.74 inches, November 1.75 inches, February and April each 2.43 inches, March 3.43 inches, December 4.05 inches, August 5.09 inches, and July, as noted above, 7.74 inches. The usual sequence of the months in this respect, and the average rainfall of each are as follows: May, September, and February each 2.52 inches, December 2.68 inches, January 2.93 inches, October 2.94 inches, March 3.31 inches, June 3.32 inches, September 3.39 inches, April 3.63 inches, November 3.78 inches, July 5.22 inches, and August 5.45 inches. Comparing the two sequences it will be seen that February, March, September, and December are the farthest removed from their accustomed positinns, changes due chiefly to a diminished rainfall in the autumn, and an increased precipitation in December; the last month, indeed, was visited by several heavy snowstorms, one being especially severe. It will be observed, further, if the months be combined into their respective seasons, that the spring, like the fall, was comparatively dry, while the summer was about as wet as usual.

Humidity. - The mean annual humidity for 1880 is expressed as $66.8^{\circ}$, saturation $=100^{\circ}$; this is a little less than the average for seven years, $67.2^{\circ}$. The month of highest mean humidity was January, its $75^{\circ}$ being as much as $2.2 \circ$ beyond its average, and that of lowest, April, with a mean humidity of $57.1^{\circ}$, or $2.5^{\circ}$ lielow its average. Between these two the months came in the following order: December with a mean humidity of $74.3^{\circ}$, August of $70.2^{\circ}$, February of $68.4^{\circ}$, November of $67.9^{\circ}$, October of $67.5^{\circ}$, March of $67.3^{\circ}$, September of $67^{\circ}$, July of $65.2^{\circ}$, June of $62.6^{\circ}$, May of $59^{\circ}$. The greatest deviations from the accustomed values, besides those of January and April just mentioned, were found in June, September, and December, the first two months falling below their averages in degrees of humidity respectively $2.8^{\circ}$ and $2.7^{\circ}$, and the latter going $1.9^{\circ}$ beyoud its mean.

Winds. - As usual in other years the prevailing direction of the wind was, in 1880 , southwesterly. In September, November, and December, however, the wind blew chiefly from the northwest, and in February from that quarter and due west equally. In June the winds were, for the most part, from due west, while during January and March northeast winds preponderated. In the latter month the wind blew with high velocity; in April there was a strong gale on the 30th day of the month.
Electricity. - Lightning was observed March 27th, and heavy thunder-storms were noted on the 4th and 7th days of April; also during May and July. In June, lightning was frequent; in August there were two auroras, on the 12 th and 13 th respectively, coinciding with hot and oppressive weather.

\section{EPIDEMICS.}

The number of deaths returned by the Registration Office of the Board of Health of Philadelphia for the year $1880^{1}$ was larger than that for any year since 1876. The whole number was 17,711 , exclusive of the still-born (870), and those deaths recorded as from "premature births" (231). The mortality is greater by 2240 deaths than that of the previous year, and gives an annual death-rate for Philadelphia, with its population of 846,980 souls (U. S. census), of 20.91 deaths to each thousand of inhabitants living, or 2.26 deaths per thousand inhabitants more than in 1879 ; the latter year, however, as I showed in my last report, ${ }^{2}$ was the healthiest to be found in the records of the Health Office since the registration of deaths had been efficiently carried out in this city. The rate of 1880 , comparatively high though it may be, is still below the average death-rate for the previous ten years (1870-1879), which I have calculated on the basis of the United States census of 1870 and that for 1880 , assuming the increase of the population during the decade to have been in equal increments for each succeeding year, to be 21.65 deaths to each thousand inhabitants living. The mortality is, also, as it is wont to be, below, and, in some instances, much below, that in the several American and foreign cities for 1880, the death-rates of which are as follows: New York 26.31 deaths per thousand inhabitants, Brooklyn 23.33, Boston 23.7, Baltimore 24.32, London 22.2, Paris 29.0, Berlin 29.9, Vienna 27.2, Amsterdam 27.2, Copenhagen 25.0, Stockholm 28.8, St. Petersburg 46.1, Madrid 40.1, Rome 32.0.3

In my report for 1879 I said that the low mortality of that year might have been anticipated from its meteorological conditions; in 1880, however, the climatic elements did not give a like favorable augury. The mildness of the early months, it is true, promised fewer deaths from diseases of the respiratory organs, but the early advent of hot weather in May, and its continuance into September, by adding to the length of the summer, the most unhealthy season of our year, gave grounds for apprehension that such reduction would be more than counterbalanced by the summer mortality, while the excessive cold of December foretold for that month more deaths from those causes which are most destructive in winter.

Of the 17,711 deaths reported, 9075 were of males, and the lesser number, 8636, of females. 'They were divided among the several ages as follows: under one year of age 4003 , or 22.6 per cent. of the total mortality; between one and two years 1285 , or 7.26 per cent.; between two and five years 1306 , or 7.37 per cent.; between five and ten years 671 , or 3.79 per cent.; between ten and fitteen yeurs 322 , or 1.82 per cent.; between fifteen and twenty years 503 , or 2.84 per cent.; between twenty and thirty years 1834, or

1 Fifty-three weeks have been counted in 1880; from the week ending January 3,1880 , to that ending January 1, 1881, inclusive. 2 'Trans. Coll. Phys. Phila, 3d Series, vol. v.

8 The death-rates of the foreign cities are taken from the annual summary of births, deaths, and causes of death in London, etc., 1880 Loudou, 1881. 
10.36 per cent. ; between thirty and forty years 16.57 , or 9.36 per cent. ; between forty and fifty years 1474 , or 8.32 per cent. ; between fifty and sixty years 1356, or 7.66 per cent. ; between sixty and seventy years 1360 , or 7.67 per cent. ; between seventy and eighty years 1174 , or 6.65 per cent. ; and beyond eighty years $\lceil 66$, or 4.32 per cent. The percentages above mark, as usual, a greater mortality in the first years of life; as many as 37.23 per cent. of the whole number of deaths occurring in children unler five years of age. In the previous exceptionally healthy year the proportion was 36.09 per cent.. a percentage not very much less, so that the greater mortality of 1880 did not fall exclusively upon the very young.

In the classification of the deaths according to their causes (Table C), 3,810 of the whole number 17,711 , or 21.51 per cent., are found in the class of Zymotic Diseases ; 4,226 , or 23.86 per cent., in that of Constitutional Diseases ; 7,191, or 40.60 per cent., in that of Local Diseases ; 1,794, or 10.13 per cent., in that of Developmental Diseases; and 673, or 3.80 per cent., in that of Violent Deaths; while 17, or one tenth of 1 per cent, are under the caption Causes not Specified, which last is made to include those cases in which the causes of death were too ill-defined to admit of proper classification. The percentage of the total mortality belonging to deaths from zymotic diseases in the previous year was 18.53, or about 2 per cent. of the mortality of 1880 less that in the latter year: on the other hand, while constitutional diseases caused 24.85 per cent., of the whole number of deaths in 1879 , this class of maladies were in 1880 responsible for 1 per cent. less of the total mortality, though, on account of the large increase in the number of deaths from all causes in 1880 , their actual mortality exceeded that from the same diseases in 1879; the proportion of deaths in 1879 from local diseases, 41.51 per cent., and that from developmental diseases, 11.58 per cent., are in each instance greater than fell to these classes in 1880 , though, as with constitutional diseases, the real number of deaths from these diseases was larger in 1880 than in 1879 ; the percentage of mortality due to violent deaths in the earlier year, 3.46 per cent., was somewhat less than that calculated for the same class in $\mathbf{1 8 8 0}$.

When we compare the actual number of deaths from zymotic diseases in the two years we find the excess in 1880 to be 943 , or about one third of the mortality in 1879. This increase was due especially to the prevalence of small-pox; measles also caused some deaths, and the mortality from typhoid fever was markedly aggravated; there were also more deaths from cholera infantum; on the other hand, scarlatina diminished the number of its victims, while diphtheria, croup, and whooping-cough each claimed for itself about the same number of deaths in the two years.

The reappearance of small-pox among the causes of death at the close of the year 1879, was followed by a mortality of 424 in 1880 . The whole number of cases of the disease reported to the Health Office during the year being $1832^{1}$ it would follow that the mortality was one death in 4.32 cases. There were, however, undoubtedly many light cases of variolous disease which failed to reach the Health Office, and even some severe ones, since it is not very difficult to hide a case when death does not occur, so that it is

1 Health Office's Annual Report, etc., 1880, page 172. Philadelphia, 1881. probable that the disease was not so fatal as it appears. According to the returns, the ratio of the deaths to cases varied very much in the several wards, for while there were twelve cases reported in the Ninth Ward with no deaths, eleven in the Thirteenth, also without a death, and seventeen cases with but one death in the 'Thirtieth, there was in the Seventeenth and Twentyeighth Wards one death to about every four cases reported.

With the exception of the Ninth and Thirteenth Wards, already mentioned, there were deaths from sinall-pox in each of the wards of the city (Table E); but the Twelfth, Twenty-seventh, and Thirtieth had each only one death from the disease, and the Eighth, Eleventh, and Twenty-first each only two. 'The most deaths were reported from the 'Twenty-eighth Ward, 119 ; but these included the deaths in the $\mathbf{M u}$ nicipal Hospital for Contagious Diseases, to which cases of small-pox from all parts of the city were taken; excluding these, 79 in number, the deaths really belonging to the ward are, however, as many as 40. In the Second $W$ ard 46 persons died from the disease, in the Fourth 34, in the Thirty-first 31, in the Nineteenth 27, in the First 21, in the Twentyfifth 20, the Third 14, and the Seventh 11. Each of the remaining wards had 10 or a less number of deaths. If we group the wards together we will find that in the southern section of the city - all that part below South Street, and east of Broad Street, comprising the First, Second, Third, and Fourth Wards - there were, in a population of 108,707 souls, deaths from small-pox to the number of 115 , or a death-rate from the disease of 10.5 to the 10,000 inhabitants; all these deaths took place in and after the month of August. In another group of wards in the northeastern quarter of the city, comprising the ward in which small-pox first appeared in the previous year, namely, the 'Twenty-tifth, the Nineteenth, the 'Thirty-first, and the 'Twenty-eighth, excluding the deaths at the Small-pox Hospital, there were 118 deaths among a population of 145,741 , or a death-rate of 8.10 per each 10,000 ; in this district the deaths were distributed throughout the whole year, though the summer was nearly exempt. These two groups of wards are the same in which the small-pox raged most fiercely in the great epidemic of $1871-72$, and again in the lesser one of 1876 . Between these two districts stretches the part of the city where the population becomes densest, the greatest movement of business is to be found, and the wealthier classes have their homes (the Fifth, Sixth, Seventh, Eighth, Ninth, Tenth, Eleventh, Twelfth, 'Thirteenth, Fourteenth, Fifteenth, Sixteenth, Seventeenth, Eighteenth, Twentieth, and Twenty-niuth Wards); here, in a population of 380,934 , there were but 85 deaths, or 2.2 to each 10,000 of inhabitants.

It may seem at first sight singular that the disease passed comparatively harmlessly over the latter region to establish itself in the southern wards with more virulence than it displayed in its birthplace, but no doubt the explanation is to be found in the greater attention paid to vaccination and cleanliness in the richer quarter of the town. In the outer circle of wards, Twenty-first (Manayunk), Twenty-second (Germantown), Twenty-third (Frankford and Bridesburg), Twenty-fourth and Twenty-seventh (West Philadelphia), Twenty-sixth and Thirtieth, the aggregate population of which is 165,206 sonls, there were but 27 deaths, or 1.6 to each 10,1100 of inhabitants. 
The distance of these districts from the focus of the disease suggests itself as the cause of their comparative exemption.

Of the deaths from small-pox, 36 were recorded for the first quarter of the year, 21 for the second, 50 for the third, and as many as 317 for the last quarter; the figures show the insidious advance of the disease, not many deaths during the first three months, then a decline in the number in the second quarter, during which the lowest monthly mortality, four, was reached; in the third quarter a rise to a number of deaths almost equal to that recorded for the whole first half of the year, and finally in the last quarter a mortality nearly three times as great as that returned for all the preceding quarters of the year, the closing month, December, claiming the maximum monthly mortality, 189. A tendency in small-pox to a diminished mortality or disappearance in the summer, and to a beginning or increase in the number of cases in the later months of the year has been shown in Philadelphia during and since the severe epidemic of 1871 1872 ; before that event registration was not full enough to have data to elucidate these points. In the epidemic mentioned the deaths from the disease began to increase in the early autumn; there was a marked rise in the mortality during the first week in October, after which the progress of the disease was very rapid; the winter gave a high mortality, but by the time the summer came the scourge had nearly disappeared, and there was no rekindling of the dying flame in that fall or the succeeding winter, the disease entirely vanishing from the causes of death in the following summer. Subsequently there was very little small-pox in Philadelphia till the fall of $187 \tilde{5}$, when a sharp increase in the number of its deaths took place, followed by a small epidemic in 1876 , which diminished, however, in mortality in the summer, to increase a little in the fall of that year, and fiually to disappear entirely in the summer of 1877 ; after which the mortuary lists were free from small-pox until the reappearance of the disease in the fall of 1879 . Briefly to recapitulate, we have the great epidemic of 1871-1872, beginuing in the fall of 1871 , the much smaller one of 1876 beginning in the autumn of 1875 , again a new appearance of the disease in the last months of 1879 , and a large increase in its mortality during the autumn of 1880 , after the deaths had diminished to a very few during the summer of that year. The Registrar-General of England, in his "Annual Summary" 1 for 1880 , calls attention to a like seasonal distribution of the deaths from small-pox in London, the observations extending over five years; but such distribution has not been generally noted in other places. It is perhaps to be accounted for in the same way that we explain the greater prevalence of typhus in winter, by the greater deficiency of ventilation in houses, and the keeping within doors at that season; conditions favorable to the accumulation and reception of the poison of the disease.

Speaking in my report for 1879 of small-pox, I detailed the measures of isolation, vaccination, revaccination, and purification of surroundings instituted by the health authorities of the city to oppose the march of the disease, and there can be no doubt that these were effective in staying its ravages; but these authorities were armed with no law to compel obedience to their mandates, and in a few months even the money appropriated to carry them out was exhausted. Then their hands were to a certain extent tied - not entirely, for vaccination and the removal of nuisances still went on, but only by the good-will of the vaccine physicians, and as regards the purification of places by more indirect methods of the health officer. Finally, after vexatious delays, more money was secured for vaccination, and the work went on more briskly. It would take, indeed, what seems to legislators an immense amount of money for such a purpose to stamp out small-pox in so large a city as Philadelphia. According to Curschman ${ }^{2}$ the duration of immunity from the disease under exposure after vaccination may be stated at from eight to ten or twelve years. If we put it at ten years there would then be required in our population of, in round numbers, 850,000 inhabitants, a yearly average of 85,000 vaccinations and revaccinations to keep the city protected; that is, one tenth of the whole population would need to have the operation performed upon it each year. 'This would cost the city, if it were responsible for the whole expense of vaccination, at the rate now paid in Philadelphia for public váccination, about $\$ 40,000$ yearly - really a very insignificant sum when the enormous benefit to be derived is considered, but immense, as I have said, in the estimation of our legislators. Of course, in reality, a very large number of persons are vaccinated or revaccinated at their own expense; how many there is no means of accurately estimating, but I should think that the city ought to be prepared to vaccinate or revaccinate at least 40,000 persons yearly, for although nothing like that proportion of persons accept gratuitous medical relief, a very large number who are willing to pay a physician when they are sick will not incur the expense of vaccination to prevent a sickness which they hope may never come upon them. In fact, there were performed in Phila delphia during the ten years preceding 1880 , in round numbers, 130,000 successful operations ; ${ }^{\mathbf{3}}$ while, if $\mathbf{m y}$ estimates are plausible, there should have been about 400,000 , or as many as 270,000 more. Adding to the last number the average yearly estimate of 85,000 to be vaccinated, Philadelphia found herself at the beginning of 1880 with about 350,000 persons to vaccinate, in order to be thoroughly protected from smallpox. These figures are not presumed to be more than approximately correct, yet they are, perhaps, close enough to the truth to show what a wide field in the direction of vaccination lay before the Health Board when confronted by the epidemic. The number of operations really paid for by the Board in 1880 (and for such only is compensation given) was but 28,415 , so that it was hardly to be expected that the end of the year would witness the abolition of the epidemic. The unprotected persons were, however, scattered throughout the whole community, and this absence of aggregation is perhaps the reason why the devastation from the disease was not greater. Those persons especially received the care of the vaccine physician who, from contiguity to the sick, were most likely to be attacked by variola. Incomplete as I have shown were the means adopted to eradicate the disease, yet, in a letter which I wrote as correspondent to the Bulletin of the National Board of Health, I claimed a certain measure of success for them in instancing in

2 Encyclopædia of the Practice of Medicine,' Ziemssen, vol. ii. p. 406, Am. Edition, New York, William Wood \& Co., 1875.

8 Records of Health Office. 
comparison the course of the disease in the neighboring city of Camden, where even so much was not done. Small-pox was imported into Camden from Philadelphia in February, 1880, and caused there, as I was informed by Dr. James Wroth, of that city, in the course of one year 131 deaths among a population of 41,638 inhabitants ; the same proportion of deaths in Philadelphia would have given 2665 for that city instead of the 424 deatlis recorded. 'The fact, however, is not to be lost sight of that epidemics are always liable to be more severe in small than large cities, probably from other causes than the want of sanitary protection.

The comparatively large number of deaths from measles, 108, the largest in any year since 1874, represents a great multitude of cases of the disease, since the affection is so rarely fatal, even with its complications. It is so contagious a malady that when it appears in a community it runs among the children like wildfire; given its occurrence in a family of the poorer classes, who use much in common, it will not only attack, with very rare exceptions, all the children under the same roof, but spread to the next house, and so on, till in a very short tine it has searched out every child in the neighborhood not protected by a previous attack of the disease.

Deaths from measles were reported from each one of the city wards but four (the Sixth, Ninth, Twentyfirst, and Twenty-seventh), so that the zymotic was very widely diffused, as follows naturally from its very contagious nature. The aggregate of deaths caused by it were, however, comparatively so few, that when divided among the twenty-seven invaded wards, the numbers for each are too insignificant to admit of profitable comparison of the respective mortality of these small divisions of the municipality. If, however, groups of wards be taken together as single districts, those, for instance, defined above in discussing the distribution of the deaths from small-pox, it will be seen that the better-placed "old city proper" had no fewer deaths than those other parts of the city which were the principal sufferers as regards small-pox. The mortality from measles was five in January, 20 in February, 38 in March, 29 in April, nine in May, and four in June, when the epidemic may be said to have come to an end, though there were three deaths subsequently, namely, one in October and two in December. It will be noted that the deaths had a small beginning in January, growing more numerous quite rapidly till the maximum was reached in $\mathbf{M a r c h}$, the month distinguished beyond all others in this climate for fatal affections of the air passages, and that they reached zero in the summer, the season when the same diseases have their lowest death-rate. Evidently those were the complications which heightened the mortality in this otherwise trivial disease.

There were fewer deaths from scarlatina in 1880 than in any year since 1872; indeed, including the latter year, there have been only four years since 1861 (at which time our records begin to be reliable) in which a lower death-rate from this fever was observed. Nevertheless, in the rural wards, to the north of the central city, the Twenty-first (Manayunk), Twenty-second (Germantown), and twenty-third (Frankford and Bridesburg), the mortality from the disease was greater than during the previous year; in the last ward the deaths increased from six in 1869 to as many as 26 , the latter giving a rate of about 10 deaths to every 10,000 inhabitants living. Tracing briefly in my report for 1879 the cause of scarlatina in previous years, I forecast this diminution of mortality in 1880, but also deemed an increase in the number of the deaths from scarlatina probable at the close of that year. ${ }^{1}$ We shall see by referring to the monthly mortality that the latter actually took place ('Table E) : January 17 deaths, February 28, March 11, April 17, May 32, June 39, July 11, August 20, September 17, October 16, November 32, and December 50 .

We find that diphtheria caused 323 deaths in 1880 , just two more than the number reported for 1879 ; its distribution through the city was not much different from that noted in the latter year, though the outlying Iwenty-second and Twenty-third Wards each counted more deaths from the zymotic; in the former (Germantown) there were 33 deaths where there had been 17 in the previous year, giving a death-rate of about 10 to the 10,000 inhabitauts in 1880 , and in the latter ward 20 deaths instead of 10 , or a death-rate increased to 7.5 to the 10,000 inhabitants ; but these figures are considerably above those which express the mortality from diphtheria throughout the whole city, which I have calculated to be 3.4 deaths to the unit of 10,000 inhabitants. The seasonal distribution of the disease was the usual one, more deaths in the cold, less in the warm, weather; 97 deaths in the first quarter of the year, 72 in the second, 41 in the third, and 101 in the last quarter. The approach to equality in the number of deaths in the years 1880 and 1879 is characteristic of the rather sluggish course of diphtheria in Philadelphia, as it changes for better or for worse; this muchdreaded disease has never taken the severe hold upon this community to which the records of some other cities bear witness.

As with diphtheria, the 303 deaths from croup, set down for 1880 , approximate quite closely in number to the 291 from the same cause in the previous year. These deaths were scattered over the whole city, but the wards forming a group in the northeastern section of the city (Sixteenth, Seventeenth, Eighteenth, Nineteenth, Twentieth, and 'Thirty-first) and two wards in the southern part of the city (Second and Twentysixth) were the greatest sufferers, the mortality in these districts being from 5 to 8 to each 10,000 inhabitants, while in the remaining wards of the city the death-rate did not exceed from 1 to 4 deaths in an equal number of people. Of the rural wards, the 'Twenty-second (Germantown) and 'Twenty-Third (Frankford and Bridesburg) had only from 1 to 2 deaths in each 10,000 inhabitants, but the 'Twentyfirst (Manayunk) had as many as 4 deaths in that number. There is nothing unusual in this distribution of the disease; the central sections of the city are wont to be less severely attacked by croup and some other of the zymotic diseases than the northeastern and southern districts, while the outlying wards vary as regards its prevalence, being sometimes classed with the more unfortunate districts, and again being in company with the less afflicted central wards of the city.

The deaths from croup were divided among the quarters of the year in a proportion strikingly similar to that recorded for diphtheria, there being in the first quarter 107 deaths, in the second 62, in the third 42,

1 Report of Meteorology and Epidemics for 1879. Transactions Coll. Phys. Phila., 3d Series, vol. v., pp. 92-93. 
and in the fourth quarter 91. The two diseases are so similar, if they be not identical, that the same case would be returned by one physician as diphtheria, and by another as croup; so that if they are really different diseases, their true relative proportion is hopelessly confused in the records.

The mortality from typhoid fever, which had been decreasing annually since 1876 , in which year it will be remembered the deaths were double the yearly average, now in 1880 advanced to 495 , an increase over the mortality of the previous year of 151 deaths, or forty-four per cent. The death-rate, 5.8 deaths to each 10,000 inhabitants living, is, however, but very little more than the average mortality from typhoid fever during the ten years preceding $1876 .^{1}$ 'This increase in the mortality from typhoid fever in 1880 extended over nearly the whole city, since there were only five wards, the Eighth, Ninth, Tenth, 'Twelfth, and 'I'wenty-sixth, in which there were fewer deaths from the fever than in the preceding year; and only two, the Eleventh and Twenty-third, in which the mortality was the same in the two years. The central wards, comprising the old "city proper" (Fifth, Sixth, Seventh, Eighth, Ninth, Ten!h Wards), were, generally speaking, the least severely visited by the disease ; here, in a population of 112,848 souls, there were 44 deaths, or a ration of 3.9 to the 10,000 inhabitants, while in the territory to the northeast (Eleventh, Twelfth, Thirteenth, Fourteenth, Sixteenth, Seventeenth, Eighteenth, Nineteenth, 'Thirty-first and 'Twenty - fifth Wards), including the old districts of Kensington and Richmond, there were, in a population of 290,733 , as many as 202 deaths, or a ratio of 6.9. In the southern section of the city (First, Second, Third, Fourth, 'Twenty-sixth and Thirtieth Wards) the ratio was but a little less favorable than the latter, being 5.9 deaths to each 10,000 inhabitants among 172,945 people. West Philadelphia ('I'wentyfourth and 'l'wenty-serenth Wards) was nearly as bad as this, having a ratio of 5.2 deaths to the 10,000 with its 69,341 inhabitants. The Fifteenth, Twentyninth, and Twenty-eighth Wards in the northwest had death-rates from the fever respectively of $4.8,6.1$, and 3.1 to the same unit, while the outlying rural wards, Twenty-first (Manayunk), and Twenty-second (Germantown), had each rates of 6.6 , and the 'Twentythird (Frankford and Bridesburg) 6 ; the last ward has had this comparatively large share of mortality from typhoid fever for several years past.

The apportionment of the deaths from typhoid fever throughout the year followed the distribution which I have so often pointed out for them. The mortality in the several months was as follows : January 39, February 29, March 35, April 27, May 31, June 24, July 40, August 65, September 46, October 38, November 29, December 72. A maximum occurred in August, and another in December, the latter appearing to have the most value, as happened really the previous year. I say appearing, because if we consult Table $D$ we will see that the month of December has been made to embrace five weeks, while that of August contains but four, so that the excess in the former month is not a real one. I have repeated a diagram, which I drew for my report for 1876 , containing a curve representing the monthly variations in the number of deaths from typhoid fever in that year, with another

1 Rep. on Met. and Epidern., Trans. Coll. Phys. Phil., 3d Series, vol. iv., page 65 . depicting the average monthly variations for the previous ten years, and $I$ have added to them a third line to show the mortality from the fever in the several months of 1880 . A truly remarkable similarity appears between all the curves, bearing wituess to the

Curves Representing the Monthly Mortality of Typhoid Fever dur1876 and 1880, and the Average Monthly Mortality of the same for Ten Years $(1866-1875)$.

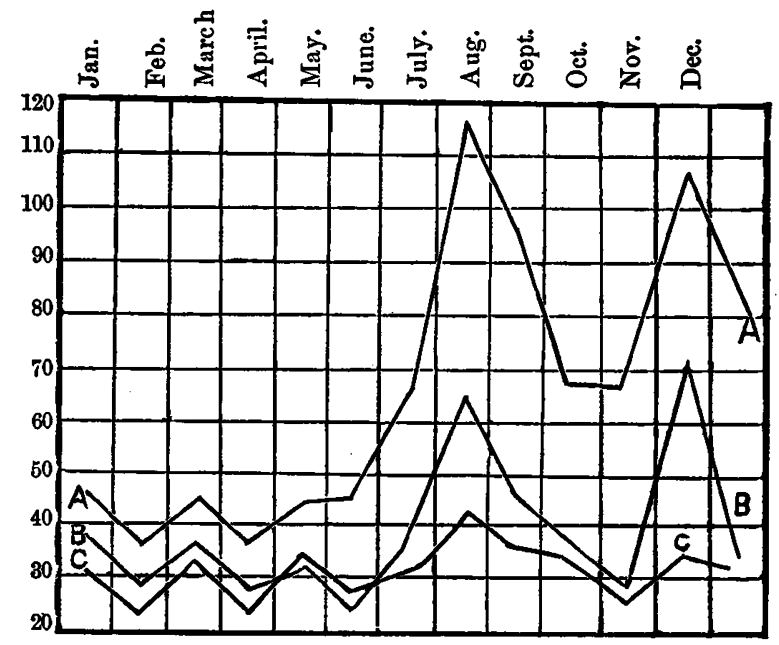

$A$. Mortality curve for 1876 . $B$. Curve for 1880 . C. Curve of averages.

constancy of "the periodical distribution" of the zymotic, and suggesting that this should always be taken into consideration when estimating the efficacy of any particular measures which may have seemed in some special instances to have successfully prevailed against the disease. The mild winter and the early aud prolonged summer doubtless played an important part in bringing about the increase in the number of deaths from typhoid fever during the latter half of the year, as $I$ attempted to show in my report for 1876 was the case under similar climatic conditions in that year.

There were reported a few deaths from typhus fever in Philadelphia in 1880 , according to the death-list, 23 ; and that some of these, at least, followed true typhus is vouched for by physicians well qualified to decide. The deaths were scattered, however, through several months (Table D), and were not numerous enough to excite apprehension of a serious epidemic.

The preponderance in the number of deaths from constitutional diseases in 1880 , already alluded to, is in most part due to a greater mortality from tubercular diseases, and especially from phthisis pulmonalis. The deaths from tabes mesenterica bear a marked relation to climatic heat, but the connection of consumption with temperature is not so apparent; if in Table $\mathrm{D}$ the fact be kept in view that some of the months are made to include five weeks, while the others contain only four, the mortality from the latter disease will be found to have been divided not very unevenly through the year. Yet a certain connection will be observed between cold and an increased death-rate among the several months, but then there will appear a paradox in the fact, that in a year so exceptionally genial as we have seen 1880 to have been, the mortality from consumption exceeded that of the previous and some other years (Table C). The explanation, of course, is that there are other factors in determin. 
ing this rate more potent than degrees of temperature ; a truism, by the way, which should lead us to the practical inference that too much is not to be expected from a change of climate as regards the effects of the climate, per se, towards the cure of a case of consumption. Experience shows that though from year to year we may have such a variation in the mortality from phthisis as has occurred between 1880 and the previous year, yet there are not those wide differences that are found in the death-rates of zymotic diseases. Hence, even if it should be proved true that fell consumption is allied to these in having for its cause some microscopic germ, it would seem that this poison is more constant in its degrees of virulence than those which occasion periodical epidemics of other diseases. We might reasonably explain the difference in the annual death-rates, since excesses of climate fail us, by changes in the modes of life - business pursuits, mental strain. It would appear then not unlikely that the revival of business, which began in the autumn of 1879 , by creating new anxieties and giving incentive to overwork, was responsible for some additional deaths from phthisis pulmonalis.

The difference in the mortality from local diseases, the 7191 deaths in this class exceeding the number in the previous year by 769 ; seems to have been due in great measure to the disturbing influence of the early accession of summer heat. It belongs chiefly to the diseases of the nervous system, and, among these, especially to cephalitis and convulsions, terms often used by those who write death-certificates to express the causes of death in infants during the hot weather. The mortality from sunstroke, in the same class, is seen to be increased from three in the previous year to 37 in 1880 , and of these as many as 23 to have occurred before the month of July (Table D), a very exceptionally early period for the climax of this disorder.

I presume, as with phthisis, the renewed activity in business will account for the larger number of deaths in 1880 classed under violent deaths; the risk of accidents is greater in the turmoil of busy life.

[The Tables referred to will be found in the Report.]

FOUR CASES OF NERVE STRETCHING FOR AFFECTIONS OF THE SPINAL CORD IN THE CLINIC OF PROFESSOR TIERSCH, LEIPZIG. NO BENEFICIAL RESULT.

REPORTED BY GEORGE L. WALTON, M. D.

These cases occurred in the clinic of Professor Tiersch in the St. Jacobs Hospital, at Leipzig, and will be interesting to add to the statistics of this operation.

In three of the cases the operation was performed at the earnest desire of the patients.

In no one of the four was the slightest permanent improvement discovered, though in three a slight transient improvement appeared in certain symptoms.

CASE I. R., a varnisher, thirty-five years old, has spastic spinal paralysis, the symptoms of which began about six years ago after an attack of typhoid fever. Since that time has complained of numbness, weakness, and dragging in the legs, together with girdling pains around the abdomen.

Status before the operation. Patient is a middlesized, well-nourished man. Interual organs normal. From the first to the twelfth dorsal vertebra is a sco- liosis with its convexity to the right; below, a compensating scoliosis with its convexity to the left.

No kyphosis. Vertebræ nowhere tender to pressure.

The upper extremities are normal, and without exaggerated reflexes. Lower extremities not atrophied, but movements are weak, especially in the left. Patient can, however, move both limbs slowly. Quick movements are impossible on account of contractions. No ataxia. Sensibility not affected. Tendon reflexes in left leg considerably, and in right slightly exaggerated.

Foot phenomenon present. The gait is purely spastic.

Both sciatic nerves were stretched as follows: $\mathrm{Pa}$ tient was chloroformed and laid on the belly. The region of the incision was shaved and carbolized. An incision was made ten centimetres in length from the lower edge of the gluteus maximus downwards. The nerve was laid free, taken out with the finger and stretched centrally and peripherally. The stretching was done so forcibly that the patient was lifted by the buttocks from the table. A drainage tube was inserted and the wound sewed with silk. Carbolized bandage.

After the operation the foot phenomenon had disappeared on both sides, and the patella reflex was much lessened. Patient could move the feet well.

First day after the operation. Patient complained of burning in the wound and prickling in the heels.

Second day. Pain has disappeared, also the reflexes in lower extremities. On attempting to walk the patient does not drag the legs as before, but raises the feet and sets them down on the whole sole. He says he moves with greater ease than before the operation.

Third day. The stitches somewhat reddened. Drainage tubes and half the stitches removed.

Fifth day. 'The remaining stitches removed as well as the antiseptic dressing. Plaster applied. The gait has now resumed its former character.

Sixth day. Wound on the right leg somewhat spread. Plaster. Complains of dragging pains in limbs.

Thirteenth day. Patella reflex again present; in the left leg, stronger than normal. Dragging pains continue in the left leg, and he complains of painful spots.

Fourteenth day. Both wounds entirely healed. Patient is out of bed and goes about.

According to the opinion of the attending surgeons as well as that of the medical side the condition of the patient is exactly the same as before the operation.

CASE II. E. H., twenty-eight years old, postmaster. Disease of the lumbar region of the cord. Patient says he has been generally well and has had no venereal disease. At the age of nineteen had cutaneous ulcers which came spontaneously.

For about four years he has had "rheumatic" pains, very severe at night, seemingly felt in the bones of the leg.

The pains have not affected his gait, and until four weeks ago he could walk well in the dark and with closed eyes. He is married and has two children, one four, and the other one year old.

One year ago he had an inflammation of the left testicle which ended in atrophy.

About four weeks ago he began to notice a difficulty in getting about, and at this time was obliged to use a cane, which had not previously been necessary.

At the end of a week he could no longer use his 